\title{
Dual effects of a targeted small-molecule inhibitor (cabozantinib) on immune-mediated killing of tumor cells and immune tumor microenvironment permissiveness when combined with a cancer vaccine
}

\author{
Anna R Kwilas ${ }^{1}$, Andressa Ardiani ${ }^{1}$, Renee N Donahue ${ }^{1}$, Dana T Aftab $^{2}$ and James W Hodge ${ }^{1 *}$
}

\begin{abstract}
Background: Growing awareness of the complexity of carcinogenesis has made multimodal therapies for cancer increasingly compelling and relevant. In recent years, immunotherapy has gained acceptance as an active therapeutic approach to cancer treatment, even though cancer is widely considered an immunosuppressive disease. Combining immunotherapy with targeted agents that have immunomodulatory capabilities could significantly improve its efficacy.

Methods: We evaluated the ability of cabozantinib, a receptor tyrosine kinase inhibitor, to modulate the immune system in vivo as well as alter the phenotype of tumor cells in vitro in order to determine if this inhibitor could act synergistically with a cancer vaccine.

Results: Our studies indicated that cabozantinib altered the phenotype of MC38-CEA murine tumor cells, rendering them more sensitive to immune-mediated killing. Cabozantinib also altered the frequency of immune sub-populations in the periphery as well as in the tumor microenvironment, which generated a more permissive immune environment. When cabozantinib was combined with a poxviral-based cancer vaccine targeting a self-antigen, the combination significantly reduced the function of regulatory $T$ cells and increased cytokine production from effector $T$ cells in response to the antigen. These alterations to the immune landscape, along with direct modification of tumor cells, led to markedly improved antitumor efficacy.
\end{abstract}

Conclusions: These studies support the clinical combination of cabozantinib with immunotherapy for the treatment of cancer.

Keywords: Cabozantinib, Cancer vaccine, Immunotherapy, Combination therapy, Immune subset conditioning, Immunogenic modulation

\footnotetext{
* Correspondence: jh241d@nih.gov

'Laboratory of Tumor Immunology and Biology, Center for Cancer Research, National Cancer Institute, National Institutes of Health, 10 Center Drive; Room 8B13, Bethesda, MD 20892, USA

Full list of author information is available at the end of the article
} 


\section{Background}

Cabozantinib, a small molecule inhibitor of multiple receptor tyrosine kinases (RTKs) [1], was approved in 2012 by the U.S. Food and Drug Administration (FDA) for the treatment of patients with progressive, metastatic medullary thyroid cancer [2]. Much of cabozantinib's efficacy in this setting may derive from its inhibition of the RET RTK $[3,4]$. Cabozantinib also inhibits MET and VEGFR2, two RTKs believed to play major roles in the growth and dissemination of cancer cells. MET, the only known receptor for hepatocyte growth factor, functions to influence cell survival, proliferation, migration, and invasion. MET signaling can also affect tumor angiogenesis by stimulating VEGF and VEGFR expression, downregulating thrombospondin-1, and inducing tubulogenesis [5]. Mutation, amplification, and/or overexpression of the gene encoding MET has been observed in many tumor types, and in many cases has been associated with increased cancer aggressiveness, poor prognosis, and acquired resistance to standard therapies [6-11]. The VEGF pathway of tumor angiogenesis has been targeted extensively with antibody and small molecule inhibitor therapies [12-14]. However, in many cases, tumors overcome the initial inhibition of angiogenesis mediated by these therapies, in some cases due to an upregulation of MET signaling [15]. The dual inhibition of MET and VEGFR2 by cabozantinib may account for its activity in additional tumor types such as metastatic castration-resistant prostate cancer, renal cell carcinoma, and hepatocellular carcinoma, in which it is currently in phase III clinical trials [16-18].

Currently, the FDA has approved a limited number of immunotherapeutic agents for the treatment of cancer. These include sipuleucel-T, an autologous dendritic-cell vaccine for prostate cancer, ipilimumab, a monoclonal antibody that blocks the CTLA-4 inhibitory signal, and most recently pembrolizumab, a PD-1 inhibitor which also joins IL-2 and interferon-alpha for the treatment of melanoma [19-23]. However, many more immunotherapies, including poxviral-based cancer vaccines, are in late-stage clinical trials and are exhibiting substantial anti-tumor activity in multiple clinical settings [24-26].

Immunotherapeutic drugs have had positive clinical results as single agents. However, given the immunosuppressive nature of cancer, there is considerable room for improvement [27-29]. Combining immunotherapy with other targeted agents that have immunomodulatory capabilities in addition to antitumor properties has the potential to enhance its clinical benefit. Our studies have focused on two mechanisms for altering antitumor immune responses: immunogenic modulation and immune subset conditioning. Immunogenic modulation has been defined as the alteration of tumor cell phenotype such that the tumor cell becomes more sensitive to $\mathrm{T}$ cellmediated lysis, most commonly through a modification of cell surface molecule expression. Standard therapies such as radiation, chemotherapy, and, most recently, androgendeprivation therapy, have been shown to induce immunogenic modulation [30-33]. Immune subset conditioning involves altering the frequency and/or activity of immune cell subsets in the periphery and the tumor microenvironment, enabling more productive immune interactions leading to improved antitumor effects. Small molecule inhibitors have been shown to induce immune subset conditioning $[34,35]$. To date, however, no cancer therapy has been shown to mediate both immunogenic modulation and immune subset conditioning.

This study sought to investigate the ability of cabozantinib to improve the sensitivity of tumor cells to immune mediated lysis through immunogenic modulation and alter the immune landscape, both peripherally and in the tumor microenvironment (immune subset conditioning). We hypothesized that such effects could enable more productive immune interactions, potentially leading to synergistic antitumor effects when combining cabozantinib with a poxviral-based cancer vaccine. Here, we show that cabozantinib can (a) modulate the phenotype of tumor cells, making them more susceptible to T cell-mediated lysis, (b) modify the composition of the peripheral and tumor microenvironment immune compartments, (c) alter immune cell function, and (d) induce sustained $\mathrm{CD}^{+}$and $\mathrm{CD}^{+} \mathrm{T}$ cell-dependent tumor regression when combined with a poxviral-based cancer vaccine. Taken together, these findings suggest that cabozantinib is capable of both immunogenic modulation and immune subset conditioning, supporting its clinical combination with cancer immunotherapy.

\section{Results}

\section{Cabozantinib reduced the proliferation of MC38-CEA} tumor cells

We used the MC38-CEA murine colon carcinoma cell line which expresses both VEGFR2 and MET (Figure 1A, inset), in addition to the human carcinoembryonic antigen (CEA), to examine the in vitro immunomodulatory effects and in vivo antitumor effects of cabozantinib. First, we determined the effect of cabozantinib on the proliferation of MC38-CEA cells. MC38-CEA cells were exposed to $2.5 \mu \mathrm{g} / \mathrm{mL}$ cabozantinib for 24,72 , or $120 \mathrm{~h}$ to model the steady-state plasma concentration achievable in humans [3]. After the designated period of treatment, cells were harvested and counted, and their viability was measured. Cabozantinib significantly reduced the proliferation of MC38-CEA cells after 72 and $120 \mathrm{~h}$ (Figure 1A). However, despite this reduction, the MC38-CEA cells continued to proliferate and their viability remained $>75 \%$ at all time points, regardless of treatment. We therefore used this dose of cabozantinib for all subsequent in vitro studies. 


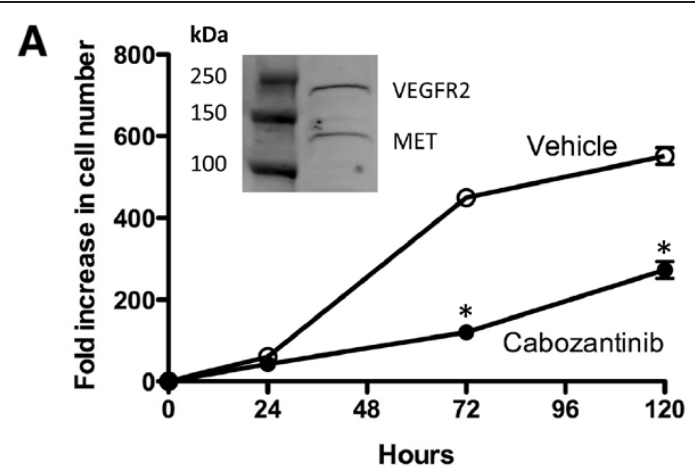

B

Phenotypic changes in MC38-CEA cells after cabozantinib treatment

\begin{tabular}{c|c|c|c|c|c|c}
\hline & CEA & H-2Kb & H-2Db & ICAM-1 & Fas & Calreticulin \\
\hline Vehicle & $68.1(6665)$ & $91.7(4458)$ & $19.2(254)$ & $0.7(301)$ & $6.1(578)$ & $4.2(141)$ \\
\hline Cabozantinib & $69.1(7070)$ & $95.0(\mathbf{8 1 3 9})$ & $\mathbf{4 0 . 5 ( 3 0 2 )}$ & $\mathbf{1 4 . 6 ( 2 3 9 )}$ & $\mathbf{3 6 . 0 ( 5 6 5 )}$ & $\mathbf{2 0 . 3 ( 1 6 8 )}$ \\
\hline
\end{tabular}

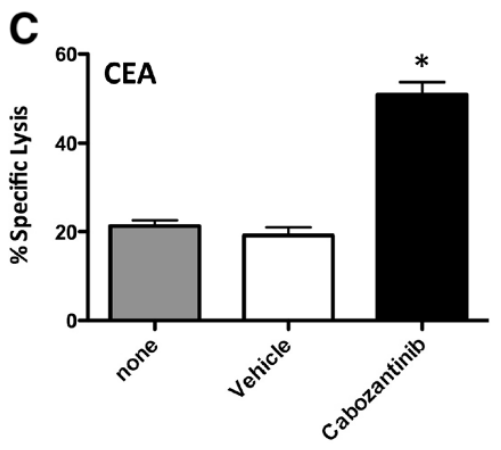

D

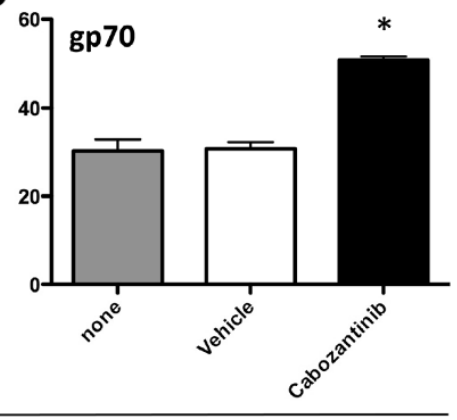

Treatment

Figure 1 Cabozantinib inhibits the growth, alters the phenotype and increases the sensitivity of MC38-CEA cells to T cell-mediated killing. (A) MC38-CEA cells were treated with $2.5 \mu \mathrm{g} / \mathrm{mL}$ cabozantinib or vehicle for 1, 3, and 5 days then assayed for growth and viability. Inset panel: MET and VEGFR2 expression of MC38-CEA cells. (B) MC38-CEA cells were exposed to $2.5 \mu \mathrm{g} / \mathrm{mL}$ cabozantinib or vehicle for $24 \mathrm{~h}$, then analyzed by flow cytometry for surface expression of CEA, MHC-I $\left(\mathrm{H}-2 \mathrm{~K}^{\mathrm{b}}, \mathrm{H}-2 \mathrm{D}^{\mathrm{b}}\right)$, ICAM-1, Fas, and calreticulin. Percent positivity and mean fluorescence intensity, in parentheses, are shown. Values in bold denote an increase of $>40 \%$ relative to vehicle-treated cells. (C, D) MC38-CEA cells treated with cabozantinib (black bars) or vehicle (open bars) or left untreated (gray bars) for $24 \mathrm{~h}$ were labeled with ${ }^{111}$ In, then coincubated with CTLS specific for CEA (C) or gp70 (D) for $18 \mathrm{~h}$ at a ratio of 30:1. Bars indicate mean \pm SEM. from quadruplicate measurements. Statistical analyses were done by Student's $t$ test. ${ }^{*}=P<0.01$. Data are representative of 3 independent experiments.

\section{Cabozantinib modulated the expression of tumor cell} markers associated with immune recognition

It has been previously shown that radiation and chemotherapy can alter the phenotype of tumor cells, rendering them more sensitive to $\mathrm{T}$ cell-mediated killing $[31,32,36]$. To determine if cabozantinib could modify the expression of cell-surface markers that influence immune recognition, we treated MC38-CEA cells with cabozantinib for $24 \mathrm{~h}$, then stained and analyzed them by flow cytometry. Cabozantinib significantly upregulated the expression of MHC-I molecules on both the population level $\left(\mathrm{H}-2 \mathrm{D}^{\mathrm{b}}\right)$ and a per-cell basis $\left(\mathrm{H}-2 \mathrm{~K}^{\mathrm{b}}\right)$, increasing the potential for antigen presentation and $\mathrm{T}$ cell recognition of the tumor cells (Figure 1B). Cabozantinib treatment also increased the percentage of MC38-CEA cells expressing ICAM-1, Fas, and calreticulin, cell-surface markers that also aid in $\mathrm{T}$ cell recognition, adhesion, and stimulation (Figure 1B). Prior studies have suggested that altering the expression of any one of these markers was capable of making tumor cells more amenable to $\mathrm{T}$ cellmediated killing [31,32,36-38].

\section{Cabozantinib increased the sensitivity of MC38-CEA cells to $\mathrm{T}$ cell-mediated killing}

To determine if cabozantinib treatment could increase the sensitivity of MC38-CEA cells to $\mathrm{T}$ cell-mediated lysis, we treated cells for $24 \mathrm{~h}$, then used them as targets in CTL killing assays. Cabozantinib treatment significantly increased the sensitivity of MC38-CEA cells to T cell-mediated lysis by cytotoxic $\mathrm{T}$ lymphocytes (CTLs) specific for CEA $(P=0.0004)$ (Figure $1 C$ ) as well as the endogenously expressed tumor antigen gp70 $(P=0.0075)$ 
(Figure 1D). We next investigated whether cabozantinib treatment made tumor cells more susceptible to killing by other therapies or if their increased susceptibility was specific to T cell-mediated killing. We treated MC38CEA cells with cabozantinib for $24 \mathrm{~h}$, then exposed them to 0 or 5 Gy external-beam radiation and replated them in the absence of cabozantinib. Cells were counted and assayed for viability 24, 48, and $72 \mathrm{~h}$ post-irradiation. Administration of external-beam radiation further reduced the growth of cabozantinib-treated MC38-CEA cells, but did not reduce their viability as the cells remained $>75 \%$ viable regardless of treatment (Additional file 1). Taken together, these data suggested that cabozantinib was capable of specifically altering tumor cells in ways that made them more amenable to immune mediated attack.

\section{Cabozantinib treatment altered the composition of the peripheral immune environment}

To assess the impact of cabozantinib treatment on the peripheral immune environment, CEA-Tg C57/BL6 mice were fed a cabozantinib-compounded diet for up to 35 days. After 10 days on this diet, mice achieved a cabozantinib serum concentration of $2.77 \pm 1.14 \mu \mathrm{g} / \mathrm{mL}$, which was similar to the steady-state serum concentration achieved at the maximum tolerated dose in a phase I human clinical trial $(2.31 \mu \mathrm{g} / \mathrm{mL}$; Figure 2A) [3]. At 35 days, cabozantinib treatment did not affect the total number of splenocytes in treated mice (Figure 2B), nor did it significantly increase the percentage of $\mathrm{CD}_{4}^{+} \mathrm{T}$ cells in the spleen $(P=0.1585)$ (Figure 2C). Cabozantinib treatment did, however, increase the percentage of $\mathrm{CD}^{+} \mathrm{T}$ cells $(P=0.0198)$ (Figure 2D). In addition, treatment with cabozantinib reduced the percentage of $\mathrm{T}$ regulatory cells (Tregs) $(P=0.0152)$ (Figure $2 \mathrm{E}$ ), and myeloid-derived suppressor cells (MDSCs) $(P<0.0001)$ in the spleen (Figure 2F). As a result of these alterations, CD4:Treg/MDSC ratios improved from 13.34 to 16.43 and 4.14 to 7.59 , respectively even in the absence of a significant change in the level of $\mathrm{CD}^{+}{ }^{+} \mathrm{T}$ cells. CD8:Treg/MDSC ratios improved from 8.24 to 11.91 and 2.54 to 5.50 , respectively, due to the significant alteration of $\mathrm{CD}^{+} \mathrm{T}$ cells, Tregs, and MDSCs. These changes in immune-cell composition were evident as early as 10 days after initiating cabozantinib treatment. In addition, after 10 days of cabozantinib treatment we observed a transient increase in the percentage of $\mathrm{CD}^{+} \mathrm{T}$ cells $(19.90 \% \pm 0.76$ vs. $27.44 \% \pm 0.65$; $P<0.0001)$; however, this increase waned by day 35 .

\section{Cabozantinib therapy synergized with a therapeutic cancer vaccine to improve $\mathrm{T}$ cell proliferation and function}

After determining that cabozantinib could alter the peripheral immune landscape, we next combined it with a poxviral-based cancer vaccine to determine if the combination could alter the function of immune cells as well. Cabozantinib and MVA/rF-CEA/TRICOM were administered to CEA-Tg C57/BL6 mice as indicated in Figure 3A. After 35 days, splenocytes were harvested and Tregs were purified to assay their ability to regulate the proliferation of naïve $\mathrm{CD}^{+} \mathrm{T}$ cells. Compared to Tregs from control mice, Tregs from mice treated with cabozantinib alone demonstrated a significantly reduced ability to regulate the proliferation of CD4 ${ }^{+} \mathrm{T}$ cells $(P=0.0183)$ (Figure $3 \mathrm{~B})$. Surprisingly, the regulatory capacity of Tregs from mice treated with MVA/rF-CEA/TRICOM alone was also significantly reduced $(P=0.0003)$ (Figure 3B). However, the combination of cabozantinib and MVA/rF-CEA/TRICOM completely abrogated Treg function, as $\mathrm{CD}_{4}^{+} \mathrm{T}$-cell proliferation in the presence of Tregs from these mice was not significantly different from that in the absence of Tregs $(P=0.0775)$ (Figure 3B). Splenocytes from these mice were also analyzed for CEAspecific cytokine production. Splenocytes from mice treated with the combination of cabozantinib and MVA/ rF-CEA/TRICOM produced significantly more interferon (IFN) $-\gamma$ (Figure 3C; $P=0.0188$ ) and tumor necrosis factor (TNF)- $\alpha$ (Figure 3D; $P=0.0015$ ) than splenocytes from control mice. In addition, splenocytes from mice treated with the combination produced significantly more IFN- $\gamma$ than splenocytes from mice receiving either cabozantinib alone $(P=0.0463)$ or MVA/rF-CEA/TRICOM alone $(P=$ $0.0020)$. Splenocytes from combination-treated mice also produced significantly more TNF- $\alpha$ than splenocytes from mice receiving MVA/rF-CEA/TRICOM alone $(P=0.0022)$.

\section{Cabozantinib treatment reduced tumor vascularity and altered immune-cell infiltration when combined with a cancer vaccine}

It has been reported that cabozantinib reduces tumor vascularity, primarily through the inhibition of VEGF receptors $[1,39,40]$. We sought to confirm this observation in the MC38-CEA model and determine whether cabozantinib could also affect infiltration of immune cells into the tumor microenvironment when combined with a cancer vaccine. We implanted CEA-Tg C57/BL6 mice with MC38-CEA cells and treated them as indicated in Figure 4A. Immunohistochemical analysis indicated that cabozantinib treatment significantly reduced the vascular density of MC38-CEA tumors compared to tumors from control-treated mice ( $P=0.0166)$, and this reduction was maintained when cabozantinib was combined with MVA/ rF-CEA/TRICOM $(P=0.0249)$ (Figure $4 \mathrm{~B}$ and $C)$. In addition, tumors from mice treated with the combination of cabozantinib and MVA/rF-CEA/TRICOM showed significantly increased infiltration of $\mathrm{CD}^{+}$lymphocytes $(P=0.0094)$ (Figure $4 \mathrm{~B}$ and $\mathrm{D}$, insert). Tumors from these mice did not show a significant increase in $\mathrm{CD}_{4}{ }^{+} \mathrm{T}$-cell infiltration (Figure 4B and E), but did show a significant 
A

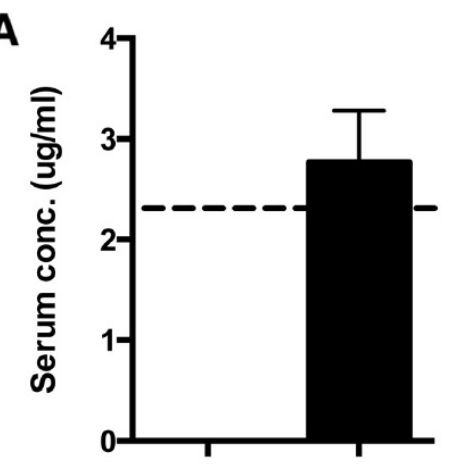

C

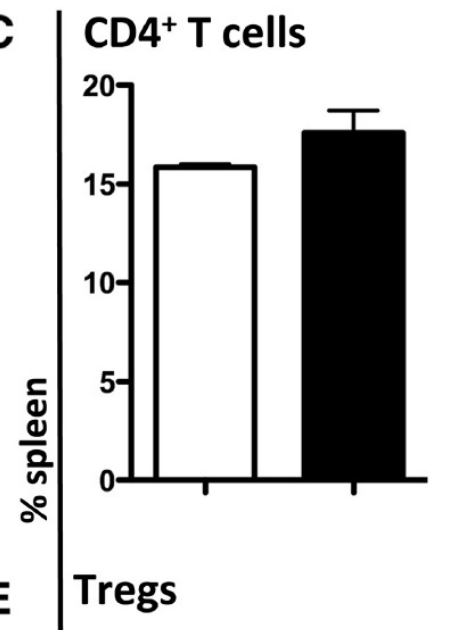

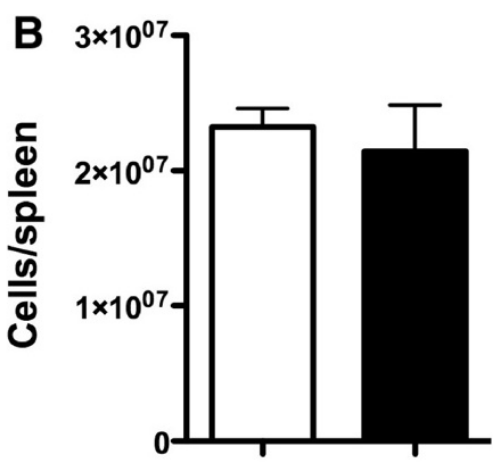

D
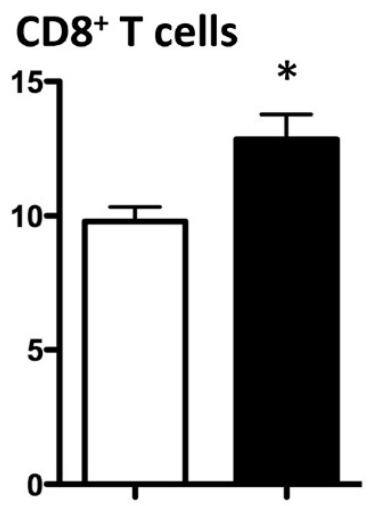

F MDSCs
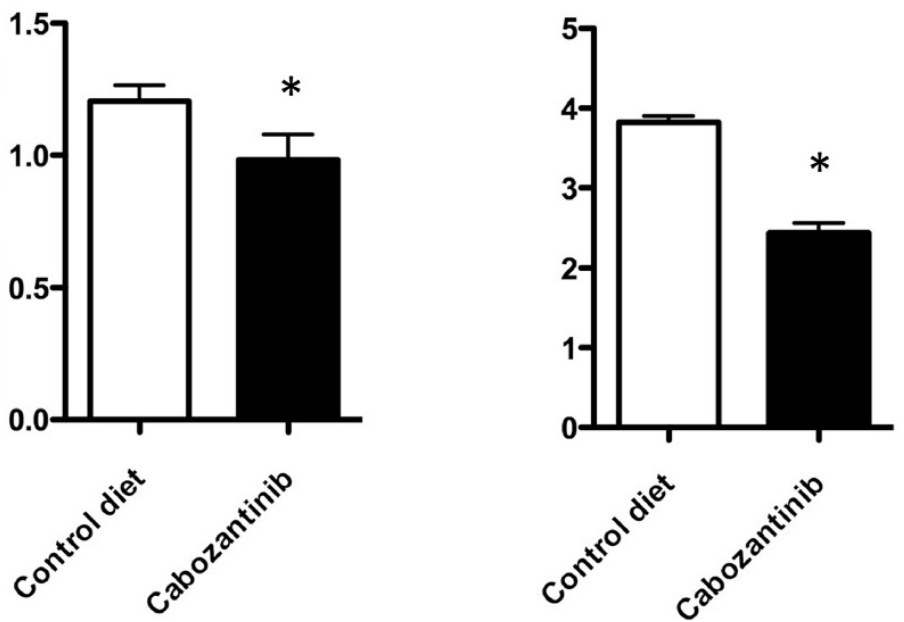

Figure 2 Cabozantinib alters the immune-cell repertoire of C57BL/6 mice. (A) Serum concentration of cabozantinib in mice fed control diet or diet containing cabozantinib for 10 days ( $n=5 /$ group). Dashed line indicates the plasma concentration achieved at the maximum tolerated dose in a phase 1 human clinical trial. (B) Number of viable cells/spleen in mice fed control diet or cabozantinib diet for 35 days. The frequency of (C) $\mathrm{CD}^{+} \mathrm{T}$ cells $\left(\mathrm{CD}^{+} \mathrm{CD}^{+}\right)$, (D) CD8 ${ }^{+} \mathrm{T}$ cells $\left(\mathrm{CD}^{+} \mathrm{CD}^{+}\right)$, (E) Tregs $\left(\mathrm{CD}^{+} \mathrm{CD}^{+} \mathrm{CD} 25^{+} \mathrm{FoxP3}^{+}\right)$, and (F) MDSCs $\left(\mathrm{CD} 11 \mathrm{~b}^{+} \mathrm{GR}-1^{+}\right)$in spleens of mice fed control diet or cabozantinib diet for 35 days was determined by flow cytometry. Error bars indicate mean \pm SEM. Statistical analyses were done by Student's $t$ test. ${ }^{*}=P<0.05$. Data are representative of 4 independent experiments.

increase in the number of infiltrating $\mathrm{CD}^{+} \mathrm{T}$ cells $(P=0.0310)$ (Figure 4B and $\mathrm{F})$. Flow cytometric analysis revealed that the tumors from mice receiving cabozantinib either alone or in combination with vaccine had a significant increase in Treg infiltration $(P=0.01-0.005, P=0.002$ 0.001 , respectively) (Figure $5 \mathrm{~A}$ ). However, cabozantinib and, to a further extent, the combination of cabozantinib and MVA/rF-CEA/TRICOM reduced the infiltration of 

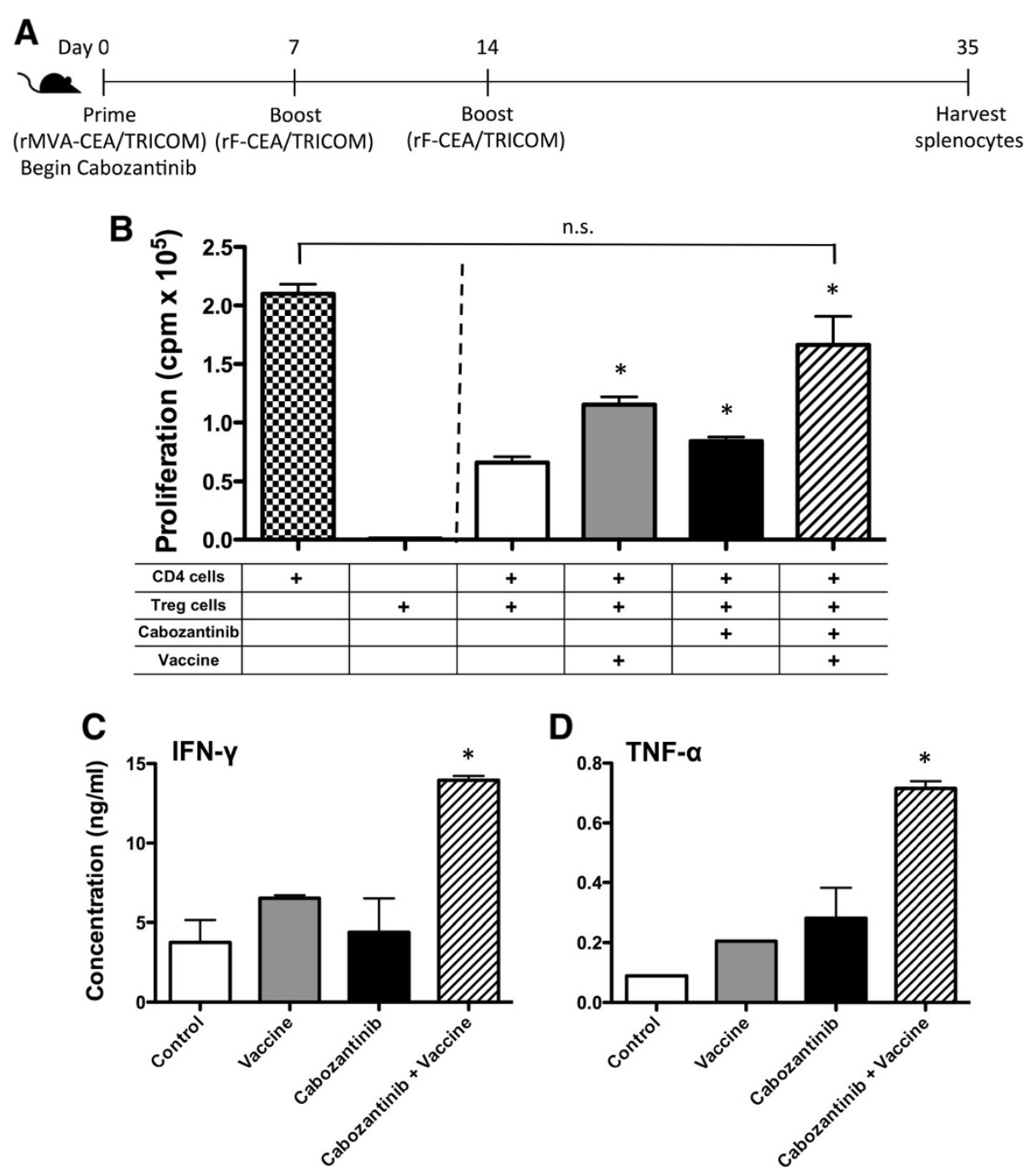

Figure 3 Combining cabozantinib with a cancer vaccine improves antigen-specific immune responses in CEA-Tg C57BL/6 mice. (A) Schema of combination therapy study $(n=9)$. (B) To evaluate Treg function, Tregs $\left(C D 3^{+} C D 4^{+} C D 25^{+} F o x P 3^{+}\right)$were isolated from spleens and cocultured with $\mathrm{CD}^{+} \mathrm{T}$ cells from naive mice, APCs (allogeneic splenocytes irradiated with $30 \mathrm{~Gy}$ ), and soluble anti-CD3 for 72 h. Control wells containing Tregs, APCs, and anti-CD3 without $C D 4^{+}$T cells were used to determine the background level of Treg proliferation. Control wells containing CD4 ${ }^{+} \mathrm{T}$ cells, APCs, and anti-CD3 without Tregs were used to determine the background level of CD4 ${ }^{+} \mathrm{T}$-cell proliferation. Error bars indicate mean \pm SEM. Statistical analyses were done by Student's $t$ test. ${ }^{*}=P<0.01$ relative to CD4 ${ }^{+}$T-cell proliferation in the presence of Tregs from untreated mice; n.s. indicates no significant difference between the proliferation of $C D 4^{+} T$ cells in the absence of Tregs or in the presence of Tregs from mice treated with combination therapy. (C, D) To evaluate CD8 ${ }^{+}$T-cell responses, harvested splenocytes were incubated with CEA peptide $(1 \mu \mathrm{g} / \mathrm{mL})$ for 7 days. Lymphocytes were then restimulated with fresh, irradiated, naïve splenocytes and $1 \mu \mathrm{g} / \mathrm{mL}$ of either CEA or HIV-gag peptide for $24 \mathrm{~h}$. Supernatants were collected and analyzed for murine IFN- $\gamma$ (C) and TNF-a (D) using a cytometric bead array. Nonspecific cytokine production in response to HIV-gag was subtracted from that induced by the CEA peptide. Error bars indicate mean \pm SEM. Statistical analyses were done by Student's $t$ test. ${ }^{*}=P<0.05$ relative to control and single-agent treatments. Data are representative of 2 independent experiments.

MDSCs $(P=0.01-0.005, P=0.005-0.002$, respectively $)$ (Figure 5B). Treatment with either cabozantinib or MVA/rF-CEA/TRICOM alone reduced the percentage of infiltrating tumor-associated macrophages (TAMs) $(P=0.01-0.005)$, but again, the combination further reduced TAM infiltration (Figure 5C). Taken together, these data show that cabozantinib induces a more immune-permissive environment, both in the periphery and at the tumor site, and that this altered environment may be exploited by combining cabozantinib with a cancer vaccine.

\section{Combination with a cancer vaccine further improved cabozantinib's antitumor activity}

We evaluated the antitumor activity of cabozantinib in the MC38-CEA tumor model with and without the 


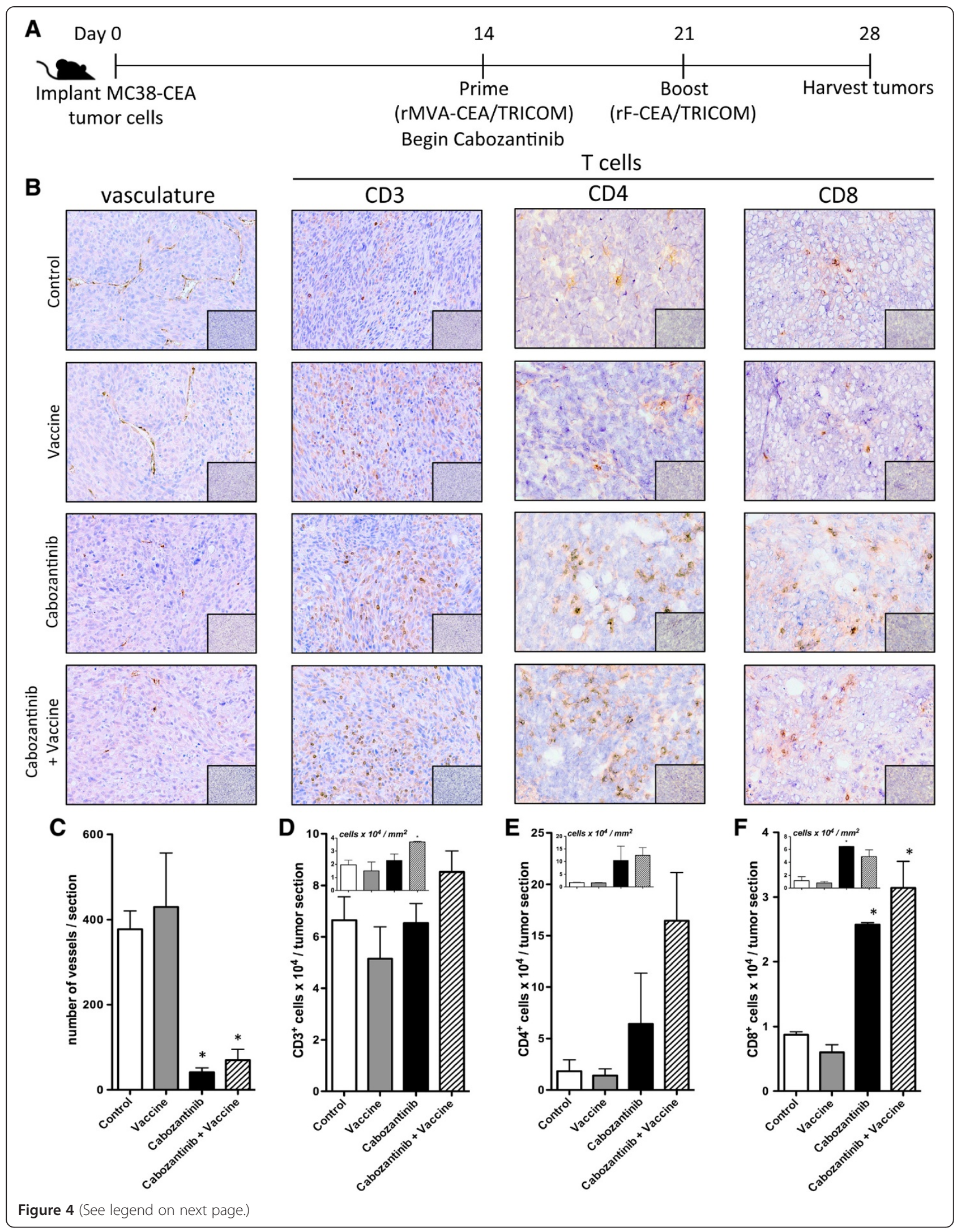


(See figure on previous page.)

Figure 4 Cabozantinib reduces tumor vascularity and improves $\mathrm{T}$ cell infiltration when combined with a cancer vaccine. (A) Schema of combination therapy study ( $n=2 /$ group). (B) Representative histological staining for indicated markers (top) on tumor sections from mice given indicated treatments (left). Inset panels: isotype staining. (C-F) Quantification of (C) blood vessels/tumor section; (D) number of CD3 ${ }^{+}$T-cells/ tumor section; (E) number of CD4 ${ }^{+}$T-cells /tumor section; and (F) number of CD8 ${ }^{+}$T-cells /tumor section. Inset panels: number of indicated cells $/ \mathrm{mm}^{2}$ of tumor. Marker staining was identified and enumerated using Aperio ImageScope image analysis software. Error bars indicate mean \pm SEM. Statistical analyses were done by Student's $t$ test. ${ }^{*}=P<0.05$ relative to control.

addition of MVA/rF-CEA/TRICOM (Figure 6A). Cabozantinib treatment alone significantly reduced the growth rate of MC38-CEA tumors compared to control (Figure 6B and D). In addition, cabozantinib induced tumor regression in one mouse; this tumor reappeared, however, by day 33. The combination of cabozantinib and MVA/ $\mathrm{rF}-\mathrm{CEA} / \mathrm{TRICOM}$ significantly reduced the growth rate of MC38-CEA tumors compared to control and MVA/ rF-CEA/TRICOM alone. Additionally, $50 \%$ of the mice treated with this combination had durable regression of their tumors and remained tumor-free through day 35 (Figure 6E). Administration of cabozantinib prior to $\mathrm{MVA} / \mathrm{rF}-\mathrm{CEA} / \mathrm{TRICOM}$ did not further improve the antitumor efficacy of the combination (data not shown). Also, discontinuing cabozantinib after 10 days of treatment, or administering a lower dose (3 $\mathrm{mg} / \mathrm{kg}$ bw/day), reduced its antitumor activity as a single agent and eliminated its synergy with MVA/rF-CEA/TRICOM (data not shown). Depleting either $\mathrm{CD}^{+}$or $\mathrm{CD}^{+} \mathrm{T}$ cells also abrogated the antitumor activity observed when cabozantinib was combined with MVA/rF-CEA/TRICOM suggesting a role for both $\mathrm{T}$ cell subsets in the increased efficacy of the combination treatment (Figure 6F).

\section{Discussion}

Multiple studies have indicated that standard cancer treatments such as chemotherapy and radiation therapy can alter the phenotype of cancer cells, making them more amenable to $\mathrm{T}$ cell-mediated lysis (immunogenic modulation), or alter the immune landscape peripherally or in the tumor microenvironment (immune subset conditioning), indicating the potential for synergy with cancer immunotherapies [27]. We have previously demonstrated synergy between sunitinib, a small molecule inhibitor, and the $\mathrm{MVA} / \mathrm{rF}-\mathrm{CEA} / \mathrm{TRICOM}$ cancer vaccine platform [34]. In our studies, sunitinib reduced the number and function of peripheral Tregs and MDSCs, induced lymphocyte proliferation, and increased the percentage of circulating and tumor-infiltrating CEA-specific $\mathrm{CD}^{+} \mathrm{T}$ cells. In tumorbearing mice, the combination of sunitinib and MVA/ rF-CEA/TRICOM reduced tumor growth and improved overall survival [34]. Here we sought to further these findings by examining cabozantinib, a novel RTK inhibitor, to determine if it could also induce immune subset conditioning due to an overlap of receptor inhibition with sunitinib. In addition, we hypothesized that, due to its slightly different range of RTK inhibition, cabozantinib could potentially induce immunogenic modulation, leading to even greater synergy with cancer immunotherapy.

We found that treatment with cabozantinib alone induced immune subset conditioning in the periphery. Cabozantinib treatment significantly increased the frequency of both $\mathrm{CD}^{+}$and $\mathrm{CD} 8^{+} \mathrm{T}$ cells in the spleen after 10 days of treatment with the increased frequency of $\mathrm{CD}^{+} \mathrm{T}$ cells being maintained through day 35 (Figure 2D). MET signaling has been shown to suppress the inflammatory response of macrophages as well as the activation and function of dendritic cells [41-43]. Cabozantinib's ability to abrogate this suppression may influence antigen presentation by professional APCs, and therefore T-cell activation, proliferation, and trafficking. Cabozantinib not only increased the frequency of effector cells, but also significantly reduced the frequency of negative immune regulatory cells (Tregs and MDSCs) (Figure 2E and F). A recent study has reported a similar reduction in circulating Tregs in metastatic urothelial carcinoma patients treated with cabozantinib, supporting the clinical relevance of this finding [44]. It has been suggested that altering the ratio between effector and regulatory cells could create an immunostimulatory environment capable of breaking tolerance, thus allowing for the develpment of an antitumor immune response against a self-antigen [45-47]. When combined with MVA/rF-CEA/TRICOM, a cancer vaccine directed toward a self-antigen, cabozantinib increased the infiltration of lymphocytes, specifically $\mathrm{CD}^{+} \mathrm{T}$ cells, into the tumor microenvironment (Figure 4D and F). Cabozantinib likely facilitated this increased $\mathrm{T}$ cell infiltration through the direct reduction/ normalization of the tumor vasculature (Figure $4 \mathrm{C}$ ) as has been described by Huang, et al. [48]. In contrast, cabozantinib reduced the infiltration of negative immune regulatory cells, MDSCs and TAMs. This effect was magnified when cabozantinib was combined with MVA/ rF-CEA/TRICOM, again generating a more permissive immune environment (Figure 5B and $\mathrm{C}$ ).

Cabozantinib alone had a significant impact on the growth of MC38-CEA tumors in vivo (Figure 6D). This effect could be primarily attributed to cabozantinib's significant impact on tumor vasculature (Figure 4C). Cabozantinib alone, however, did not induce durable tumor regression, without regrowth prior to day 35 of treatment. Complete tumor regression, without regrowth, 


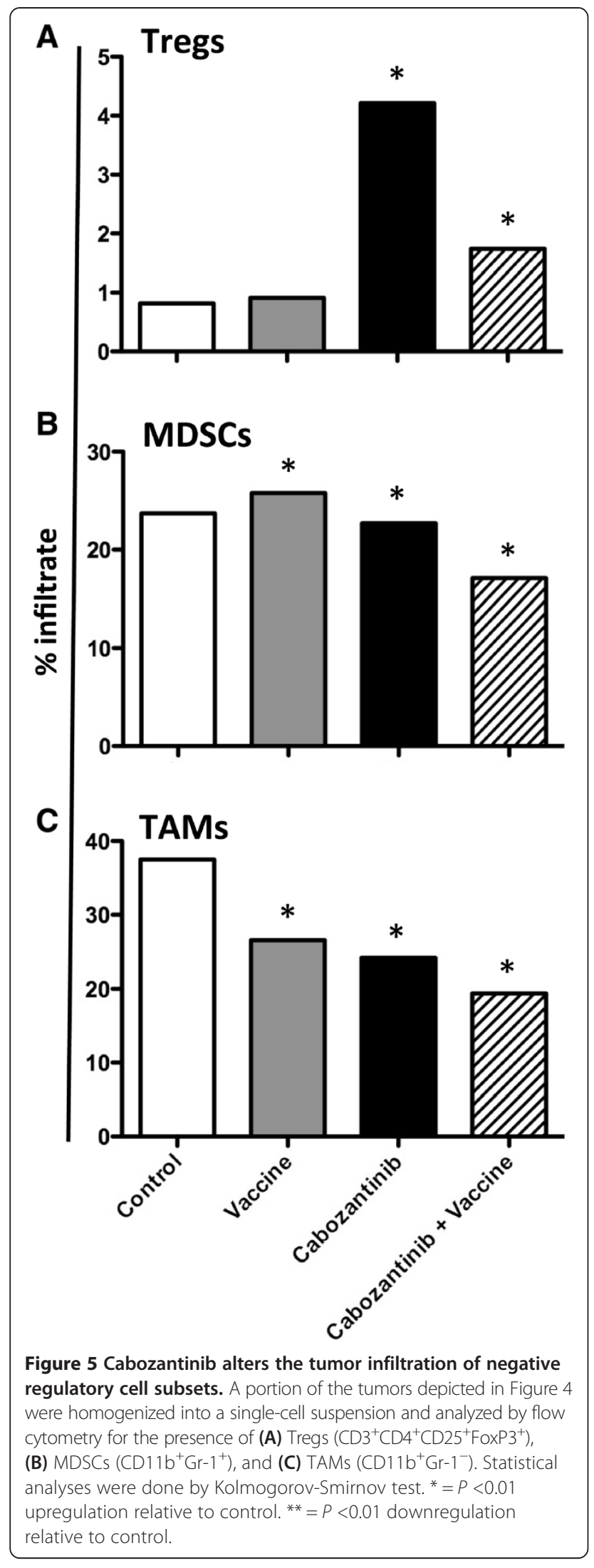

was seen only when cabozantinib was combined with MVA/rF-CEA/TRICOM (Figure 6E) and required the presence of both $\mathrm{CD}^{+}$and $\mathrm{CD}^{+} \mathrm{T}$ cells (Figure $6 \mathrm{~F}$ ). This observation has been previously noted with this vaccine platform and is likely due to a need for $\mathrm{CD} 4^{+}$cytokine support by antigen specific $\mathrm{CD}^{+} \mathrm{T}$ cells [49]. Cabozantinib also demonstrated increased efficacy when administered prior to vaccine (data not shown). It is possible that the reduced vascular density and increased lymphocytic infiltration of the tumor, induced by cabozantinib treatment alone, was sufficient to reduce the growth rate of tumor cells but not sufficient to induce enough tumor-cell death to eliminate the tumor. The addition of a cancer vaccine further reduced the function of negative immune regulatory cells and improved the function of antigenspecific effector cells, leading to tumor eradication (Figures 3B,C,D and 6E). A lower dose of cabozantinib (3 mg/kg bw/day) did not synergize with MVA/rF-CEA/ TRICOM to induce tumor regression (data not shown), suggesting that a minimum serum concentration of cabozantinib is required to achieve synergistic results. Also, if cabozantinib was discontinued after 10 days, tumor regression was not observed (data not shown), suggesting that cabozantinib levels must be maintained during vaccine treatment to achieve synergistic results.

Remarkably, despite its significant antitumor activity, cabozantinib treatment induced an increase in Treg infiltration into the tumor microenvironment, an increase that was maintained, though to a lesser degree, when cabozantinib was combined with vaccine (Figure 5A). The functional capacity of tumor infiltrating Tregs was not assayed, however, we were able to demonstrate that cabozantinib treatment significantly reduced the ability of peripheral Tregs to perform their regulatory function (Figure 3B). MVA/rF-CEA/TRICOM treatment alone similarly reduced the suppressive activity of Tregs. To our knowledge this is the first time a cancer vaccine, when used alone, has been shown to interfere with the negative regulatory capacity of these cells. The combination of cabozantinib and MVA/rF-CEA/TRICOM, however, reduced the regulatory capacity of peripheral Tregs in this mouse model to such an extent that they had no effect on the proliferation of naive $\mathrm{CD}^{+} \mathrm{T}$ cells (Figure $3 \mathrm{~B}$ ). This suggests that while the number of Tregs in the tumor microenvironment may increase with this therapeutic regimen, their regulatory capacity may be impaired.

In these studies, we demonstrated that cabozantinib treatment could not only modulate the immune landscape both peripherally and intratumorally, but we also determined that cabozantinib could induce phenotypic changes in MC38-CEA tumor cells that increased their sensitivity to T cell-mediated lysis, hallmarks of immunogenic modulation. Specifically, cabozantinib treatment upregulated 

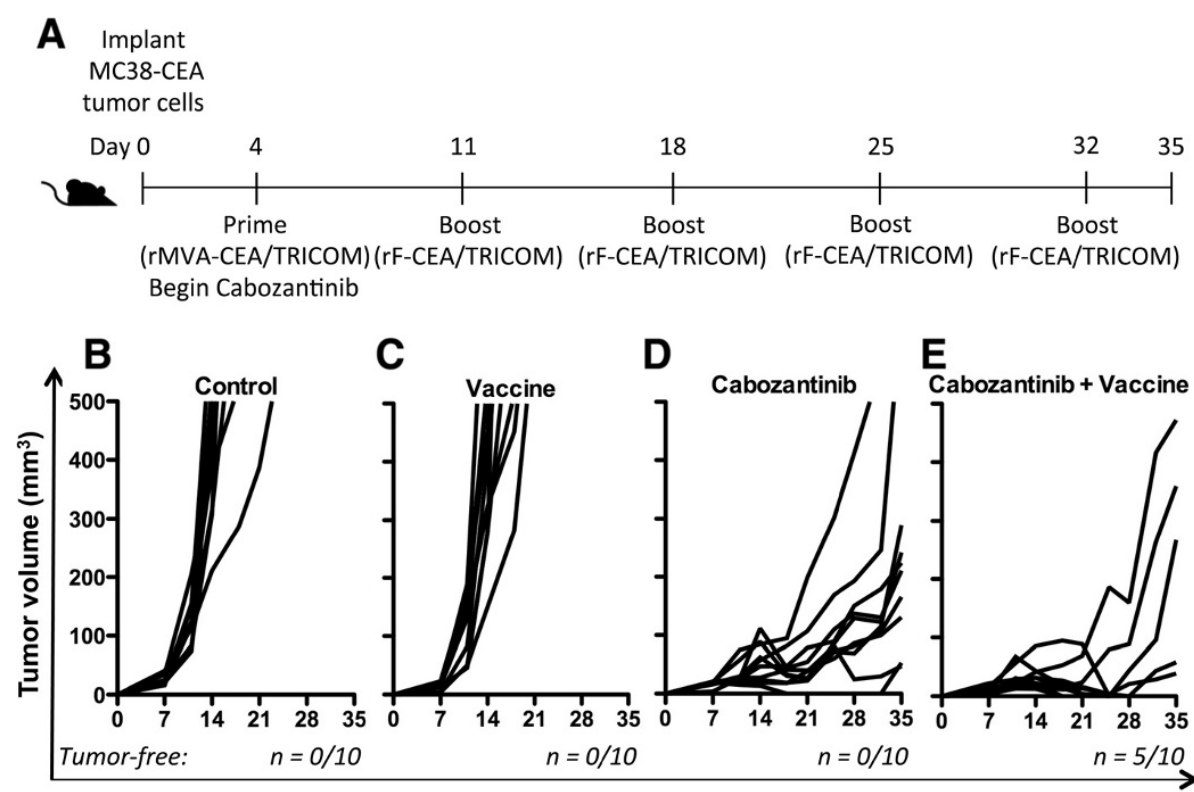

Days post-tumor implantation

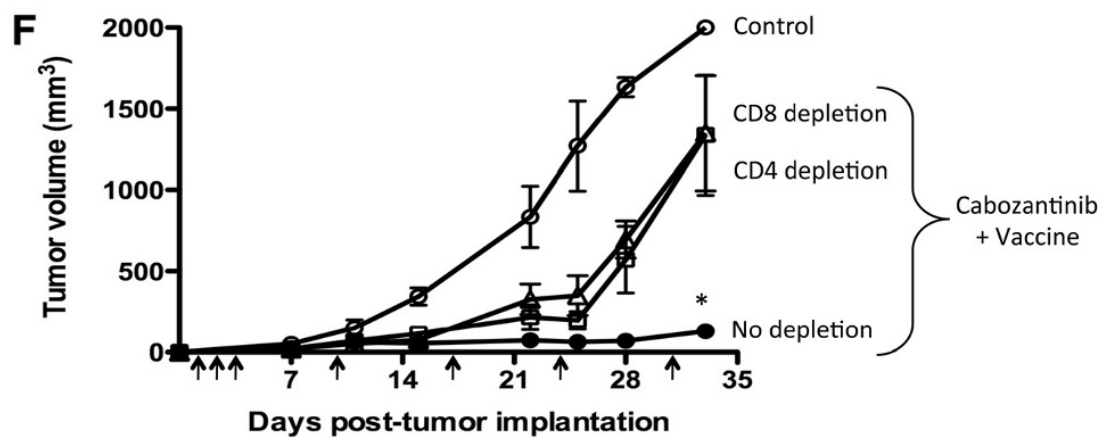

Figure 6 The combination of cabozantinib and immunotherapy significantly reduced tumor growth in a T cell-dependent manner. (A) Schema of combination therapy study ( $n=10 /$ group). Tumor growth in mice treated with (B) control, (C) vaccine, (D) cabozantinib, and (E) combination therapy, including the number of tumor-free mice at day 35. (F) To determine the role of T cells in the efficacy of combination therapy, we measured tumor growth in control mice with no depletion (open circles), mice receiving combination therapy with no depletion (closed circles), and mice receiving combination therapy in the absence of $\mathrm{CD}^{+} \mathrm{T}$ cells (open squares) or $\mathrm{CD} 8^{+} \mathrm{T}$ cells (open triangles) $(n=8)$. Depletion antibodies were administered on days 1-3, 10, 17, 24, and 31 (arrows). Tumor dimensions were measured weekly. Error bars indicate mean \pm SEM. Statistical analyses were done by Student's $t$ test. ${ }^{*}=P<0.0001$ relative to control.

the expression of MHC-I molecules, ICAM-1, Fas, and calreticulin on tumor cells (Figure 1B). We have previously shown that radiation and chemotherapy can increase the sensitivity of tumor cells to T cell-mediated lysis through upregulation of these same molecules [31-33,37]. Indeed, cabozantinib treatment increased the sensitivity of MC38-CEA cells to lysis mediated by T cells specific for either CEA or gp70 (Figure 1C and D). The observation that cabozantinib treatment did not make MC38-CEA cells more sensitive to the cytotoxic effects of radiation (Additional file 1) suggests that cabozantinib's alteration of the tumor cells is likely purely immunogenic. To our knowledge, this is the first time that a small molecule inhibitor has been shown to induce immunogenic modulation, and the first time that a single agent has been shown to induce both immunogenic modulation and immune subset conditioning.

\section{Conclusions}

Combination therapy for the treatment of cancer is becoming more common as studies continue to demonstrate the complexity of cancer progression and the ability of cancer cells to become resistant to single-agent therapy, particularly that of small molecule inhibitors. Optimally, combined therapies should synergize to produce greater anticancer efficacy than that achieved by either therapy alone. The data presented here demonstrate that, in addition to its inherent antitumor properties, cabozantinib is capable of both immunogenic modulation and immune subset conditioning, two qualities displayed 
by therapies that synergize with cancer immunotherapy. Collectively, these data support the clinical investigation of combination therapy with cabozantinib and cancer vaccines for the treatment of solid tumors.

\section{Methods and materials Animals}

Eight- to 12-week-old female C57/BL6 mice were obtained from the National Cancer Institute's Frederick Cancer Research Facility, Frederick, MD. CEA-transgenic (CEA-Tg) mice homozygous for the expression of human CEA were generously provided by Dr. John Shively (Beckman Research Institute, City of Hope National Medical Center, Duarte, $\mathrm{CA}$ ) and were bred and maintained at the National Institutes of Health (Bethesda, MD) [50].

\section{Tumor cells}

Murine colon carcinoma MC38 cells expressing human CEA (MC38-CEA) were generated by retroviral transduction of MC38 cells with CEA cDNA, as previously described [51]. MC38-CEA cells were cultured in complete medium (DMEM supplemented with 10\% fetal bovine serum, $2 \mathrm{mM}$ glutamine, $1 \mathrm{mM}$ HEPES buffer, $50 \mu \mathrm{g} / \mathrm{mL}$ gentamicin, $100 \mathrm{IU} / \mathrm{mL}$ penicillin, $100 \mu \mathrm{g} / \mathrm{mL}$ streptomycin, and $300 \mu \mathrm{g} / \mathrm{mL} \mathrm{G418)} \mathrm{at} 37^{\circ} \mathrm{C} / 5 \% \mathrm{CO}_{2}$.

\section{Drug preparation}

For in vitro studies, cabozantinib malate salt (Exelixis Inc., South San Francisco, CA) was dissolved in DMSO (vehicle) at $1.0 \mathrm{mg} / \mathrm{mL}$ and stored at $-20^{\circ} \mathrm{C}$. A dose of $2.5 \mu \mathrm{g} / \mathrm{mL}$ was used for all in vitro experiments. For in vivo studies, cabozantinib was admixed into standard rodent diet (Research Diets, New Brunswick, NJ) at a concentration of $66.7 \mathrm{mg} / \mathrm{kg}$ of diet in order to deliver $10 \mathrm{mg} / \mathrm{kg}$ bw/day to the animals. To determine the steady-state serum level of cabozantinib achieved by delivering the drug via rodent diet, CEA-Tg C57BL/6 mice $(n=5)$ were fed control diet or cabozantinib-containing diet for 10 days. Peripheral blood, acquired by retro-orbital bleeding, was analyzed for cabozantinib concentration by LC-MS.

\section{Poxviral vaccine constructs}

Modified vaccinia Ankara (MVA) and recombinant fowlpox $(\mathrm{rF})$ viruses containing transgenes for the murine costimulatory molecules B7-1, ICAM-1, and LFA-3 (designated TRICOM) in combination with the human CEA transgene (MVA/rF-CEA/TRICOM) have been previously described [52]. For in vivo studies, a priming dose of MVA-CEA/TRICOM was administered s.c., with weekly boosts of rF-CEA/TRICOM, both at $1 \times 10^{8}$ plaque-forming units/mouse/dose.

\section{Western blotting}

MET and VEGFR2 expression was determined by western blot using rabbit polyclonal antibodies to MET and VEGFR2 (Abcam, Cambridge, MA). MC38-CEA cells were lysed using Cell Lysis Buffer containing $1 \mathrm{mM}$ PMSF (Cell Signalling, Danvers, MA) and $10 \mu \mathrm{L} / \mathrm{mL}$ HALT Protease/Phosphatase Inhibitor Cocktail (Thermo Scientific, Rockford, IL) according to the manufacturer's protocol, blots were imaged using the Odyssey Infrared Imaging System (LI-COR Biosciences, Lincoln, NE).

\section{In vitro proliferation analysis}

To investigate the effect of cabozantinib on MC38-CEA cell proliferation, cells were plated in 24-well plates and treated with cabozantinib or vehicle (DMSO) in vitro for 1,3 , or 5 days, then harvested and counted using trypan blue counterstaining. To examine the effects of radiation on cabozantinib-treated MC38-CEA cells, cells were treated with cabozantinib for $24 \mathrm{~h}$, then irradiated (0 or 5 Gy) by exposure to a Cs-137 source using a Gammacell-1000 (AECL/Nordion, Kanata, Ontario, Canada), and then replated. Cells were again harvested at 24,48 , and $72 \mathrm{~h}$ post-irradiation, counted, and assayed for viability using trypan blue.

\section{In vitro phenotypic analysis}

To analyze the effect of cabozantinib on in vitro expression of immune-relevant proteins, MC38-CEA cells were treated with cabozantinib or vehicle for $24 \mathrm{~h}$, then stained with the following antibodies: CD66e/CEA-FITC (AbD Serotec, Raleigh, NC), H-2K $\mathrm{K}^{\mathrm{b}}$-APC (eBioscience, San Diego, CA), H-2D b -PE, CD54/ICAM-I-PE, CD95/FasFITC (BD Biosciences, San Jose, CA) and calreticulin-APC (R\&D Systems, Minneapolis, MN). 7AAD (BD Biosciences) staining was used to determine cell viability. Cells were incubated with the antibodies for $30 \mathrm{~min}$ at $4^{\circ} \mathrm{C}$, acquired on an LSR II flow cytometer (Becton Dickinson, Franklin Lakes, NJ), and analyzed using FlowJo software (TreeStar, Inc., Ashland, OR).

\section{Cytotoxic T lymphocyte killing assay}

To evaluate cabozantinib's ability to alter the sensitivity of MC38-CEA cells to lysis by CTLs, cells were treated with cabozantinib, vehicle or left untreated for $24 \mathrm{~h}$, after which they were harvested and used as targets in a standard CTL assay. Cells were labeled with ${ }^{111}$ In-labeled oxyquinoline (Medi-Physics Inc., Arlington Heights, IL) and coincubated in 96-well round-bottom plates at $37^{\circ} \mathrm{C} / 5 \% \mathrm{CO}_{2}$ with T572- or gp70-specific effector cells in the absence of cabozantinib at an effector:target ratio of 30:1. The $\mathrm{H}-2 \mathrm{D}^{\mathrm{b}}$-restricted CEA-specific CD8 ${ }^{+}$CTL line, T572, recognizes the peptide epitope $\mathrm{CEA}_{572-579}$, as previously described [53]. The $\mathrm{H}-2 \mathrm{~K}^{\mathrm{b}}$-restricted gp70-specific $\mathrm{CD}^{+}$ CTL line, gp70, recognizes the peptide epitope $\mathrm{p} 15 \mathrm{e}_{604-611}$ 
of glycoprotein 70 of an endogenous murine retrovirus, as previously described [54]. After $18 \mathrm{~h}$, supernatants were harvested and analyzed for the presence of ${ }^{111}$ In using a WIZARD2 Automatic Gamma Counter (PerkinElmer, Waltham, MA). The percentage of tumor lysis was calculated as follows: \% tumor lysis $=[($ experimental $\mathrm{cpm}-$ spontaneous $\mathrm{cpm}) /($ maximum cpm - spontaneous cpm $)] \times 100$.

\section{In vivo studies}

\section{Analysis of immune cell populations}

To analyze immune cell populations in the presence or absence of cabozantinib, CEA-Tg C57BL/ 6 mice ( $n=5 /$ group) were fed control or cabozantinib-containing diet for 10 or 35 days. Spleens were harvested and adjusted to a singlecell suspension. Red blood cells were removed using ACK Lysing Buffer (Quality Biologicals Inc., Gaithersburg, MD). Remaining splenocytes were blocked with mouse Fc Block (BD Biosciences) for $30 \mathrm{~min}$ at $4^{\circ} \mathrm{C}$, then stained with the following antibodies: CD3e-V500, CD4-AF700, CD8a-Pacific Blue, CD25-FITC, CD11b-V500, Gr-1AF700, CD49b-FITC, CD19-PE-Cy7, CD11c-PerCPCy5.5 (BD Biosciences) and MHC II-APC (eBioscience) for $60 \mathrm{~min}$ at $4^{\circ} \mathrm{C}$. For intracellular staining of cells with FoxP3$\mathrm{PE}$, cells were incubated with Fixation/Permeabilization solution for $16 \mathrm{~h}$ at $4^{\circ} \mathrm{C}$, then incubated with the antibody in Permeabilization Buffer (eBioscience) for $60 \mathrm{~min}$ at room temperature. All samples were acquired on an LSR II flow cytometer and analyzed using FlowJo software.

\section{Immune cell function assays}

To assess the effect of cabozantinib and MVA/rF-CEA/ TRICOM on immune cell function, CEA-Tg C57BL/6 mice were divided into 4 groups ( $n=5 /$ group): (a) control, (b) cabozantinib alone, (c) MVA/rF-CEA/TRICOM alone, and (d) cabozantinib + MVA/rF-CEA/TRICOM. Mice receiving cabozantinib were fed cabozantinib-containing diet on days 0-35. Mice receiving MVA/rF-CEA/TRICOM received a priming vaccination with MVA-CEA/ TRICOM on day 0 , then booster vaccinations with rFCEA/TRICOM on days 7 and 14. Spleens were harvested on day 35. To examine the function of Tregs, splenocytes were purified by Histopaque gradient (Sigma-Aldrich, St. Louis, $\mathrm{MO}$ ), then $\mathrm{CD} 4^{+} \mathrm{CD} 25^{+}$Tregs were purified using a Regulatory T Cell Isolation Kit (Miltenyi Biotec, Auburn, CA) according to the manufacturer's instructions. Purified Tregs were plated with antigen presenting cells (APCs), irradiated (30 Gy) splenocytes from naïe C57BL/6 mice, $\mathrm{CD}^{+} \mathrm{T}$ cells, purified from naïve $\mathrm{C} 57 \mathrm{BL} / 6$ mice using a CD4+ T Cell Isolation Kit (Miltenyi Biotec), and antiCD3 cross-linking antibody (BD Biosciences) for $72 \mathrm{~h}$. $\left[{ }^{3} \mathrm{H}\right]$-thymidine was added to the culture for the last $12 \mathrm{~h}$ of incubation. Control wells containing Tregs, APCs, and anti-CD3 without $\mathrm{CD}^{+}{ }^{+}$cells were used to determine the background level of Treg proliferation. Control wells containing $\mathrm{CD}^{+}$cells and Concanavalin A (Sigma-Aldrich) were used to determine the maximum level of $\mathrm{CD} 4^{+}$cell proliferation. Cells were harvested using a Tomtec cell harvester (Wallac Inc., Gaithersburg, MD) and $\left[{ }^{3} \mathrm{H}\right]$-thymidine incorporation was measured using a Wallac 1205 Betaplate MicroBeta Counter (Wallac Inc.) To examine cytokine production by effector T cells, splenocytes were incubated with $\mathrm{CEA}_{572-579}$ peptide (GIQNSVSA) (CPC Scientific, Sunnyvale, CA) for 7 days then purified on a Histopaque gradient. Effector cells were plated with APCs in the presence of $\mathrm{CEA}_{572}$ peptide for $24 \mathrm{~h}$. Supernatants were collected and analyzed for the presence of cytokines using a mouse Th1/Th2 Cytometric Bead Array (BD Biosciences). Data were acquired using a FACScan flow cytometer and analyzed using BD CBA analysis software (Becton Dickinson).

\section{Characterization of the tumor microenvironment}

To investigate the effect of cabozantinib and MVA/rFCEA/TRICOM on tumor vascularity and immune cell infiltration, CEA-Tg C57BL/6 mice were implanted with $3 \times$ $10^{5}$ MC38-CEA cells s.c. in the right flank. Fourteen days post tumor implantation, when tumors were established $\left(\sim 300 \mathrm{~mm}^{3}\right)$, mice were divided into 4 groups $(n=2$ / group): (a) control, (b) cabozantinib alone, (c) MVA/rFCEA/TRICOM alone, and (d) cabozantinib + MVA/rFCEA/TRICOM. Mice treated with cabozantinib were fed cabozantinib-containing diet on days 14-28. Mice treated with MVA/rF-CEA/TRICOM received a priming vaccination with MVA-CEA/TRICOM on day 14 and a booster vaccination with $\mathrm{rF}-\mathrm{CEA} / \mathrm{TRICOM}$ on day 21 . On day 28 , tumors were harvested with a portion of each tumor being fixed with Z-Fix (Anatech Ltd., Battle Creek, MI), frozen in OTC (Electon Microscopy Sciences, Hatfield, PA), or dissociated according to the protocol for preparation of single-cell suspensions from implanted mouse tumors (Miltenyi Biotec). Fixed tumor sections were stained with antibodies to von Willebrand factor at 1:1200 and CD3 at 1:1000 (Dako, Carpinteria, CA). Frozen tumor sections were stained with rat monoclonal antibodies to CD4 and CD8 at 1:1500 and 1:700, respectively (Novus Biologicals, Littleton, CO). Control sections were stained with matched isotype antibodies. Entire tumor sections were digitally scanned by an Aperio ScanScope CS scanning system and analyzed by Aperio ImageScope Viewer software (Aperio Technologies Inc., Vista, CA) excluding necrotic regions. Positive tumor regions were determined using the Microvessel Analysis v1 and Positive Pixel Count v9 algorithms, respectively and are depicted as number of vessels or cells/ tumor. Dissociated tumor was stained for flow cytometric analysis using the same antibodies and protocol as the splenic immune cell population analysis with the inclusion of CD45-BV605 (ebioscience). 


\section{Antitumor studies}

To examine the antitumor effects of cabozantinib and MVA/rF-CEA/TRICOM, CEA-Tg C57BL/6 mice were implanted with $3 \times 10^{5} \mathrm{MC} 38$-CEA cells s.c. in the right flank on day 0 . On day 4 , when tumors became palpable, mice were divided into 4 groups ( $n=10$ /group): (a) control, (b) cabozantinib alone, (c) MVA/rF-CEA/TRICOM alone, and (d) cabozantinib + MVA/rF-CEA/TRICOM. Mice treated with cabozantinib were fed cabozantinibcontaining diet on days 4-35. Mice treated with MVA/ $\mathrm{rF}-\mathrm{CEA} / \mathrm{TRICOM}$ received a priming vaccination with MVA-CEA/TRICOM on day 4, then weekly booster vaccinations with rF-CEA/TRICOM. Tumor dimensions were measured twice weekly and tumor volumes were calculated as follows: (length $\times$ width $\left.^{2}\right) / 2$. For depletion studies, MC38-CEA-bearing CEA-Tg C57BL/6 mice ( $n=8$ / goup) were given either anti-CD4 (GK 1.5) or anti-CD8 (Lyt 2.2) hybridomas i.p. on days 1-3, then at weekly intervals, or left untreated. Depletion was confirmed by flow cytometric analysis of peripheral blood. All mice, except for those in the control group, received cabozantinibcontaining diet on days 4-33, a priming vaccination with MVA-CEA/TRICOM on day 4, then weekly booster vaccinations with $\mathrm{rF}-\mathrm{CEA} / \mathrm{TRICOM}$.

\section{Statistical analysis}

GraphPad Prism 5 statistical software (GraphPad Software, La Jolla, CA) was used to measure 2-tailed unpaired Student's $t$ tests for differences between groups, with a 95\% confidence interval. All data represent the mean \pm SEM for the indicated number of replicates or individual mice. FlowJo software was used to determine significant differences in the distribution of flow cytometry data using the Kolmogorov-Smirnov test.

\section{Additional file}

Additional file 1: Cabozantinib treatment does not increase the sensitivity of MC38-CEA cells to external-beam radiation.

\section{Abbreviations}

RTKs: Receptor tyrosine kinases; FDA: Food and Drug Administration; CTLA-4: Cytotoxic T-lymphocyte-associated protein 4; CEA: Carcinoembryonic antigen; MHC: Major histocompatibility complex; ICAM-1: Intercellular Adhesion Molecule 1; CTLs: Cytotoxic T lymphocytes; CEA-Tg: C57/BL6 mice transgenic for human CEA; Tregs: T regulatory cells; MDSCs: Myeloid derived suppressor cells; MVA: Modified vaccinia Ankara; rF: Recombinant fowlpox virus; TRICOM: Triad of costimulatory molecules including B7-1, ICAM-1, LFA-3; LFA-3: Lymphocyte function-associated antigen 3; MVA-CEA/ TRICOM: MVA expressing human CEA and TRICOM; rF-CEA/TRICOM: rF expressing human CEA and TRICOM; MVA/rF-CEA/TRICOM: Prime/boost vaccination strategy administering MVA-CEA/RICOM as a priming vaccination

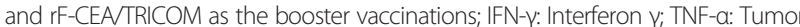
necrosis factor a; TAMs: Tumor associated macrophages; DMSO: Dimethylsufoxide; LC-MS: Liquid chromatography-mass spectrometry; PMSF: Phenylmethanesulfonyl fluoride; FITC: Fluorescein isothiocyanate; PE: Phycoerythrin; APC: Allophycocyanin; cpm: Counts per minute; APCs: Antigen presenting cells; SEM: Standard error of the mean.

\section{Competing interests}

The authors declare that they have no competing interests.

\section{Authors' contributions}

ARK planned and carried out the in vivo and in vitro experiments, analyzed the data and drafted the manuscript. AA and RD assisted with in vivo experiment planning and execution. DTA supplied the cabozantinib. JWH participated in the study design, data analysis and helped to draft the manuscript. All authors read and approved the final manuscript.

\section{Acknowledgements}

The authors thank Dr. Jeffrey Schlom for helpful suggestions, Marion Taylor for technical support, and Bonnie L. Casey for editorial assistance in the preparation of this manuscript.

\section{Author details}

'Laboratory of Tumor Immunology and Biology, Center for Cancer Research, National Cancer Institute, National Institutes of Health, 10 Center Drive; Room 8B13, Bethesda, MD 20892, USA. Exelixis, Inc., South San Francisco, CA, USA.

Received: 10 September 2014 Accepted: 9 October 2014

Published online: 13 November 2014

\section{References}

1. Yakes FM, Chen J, Tan J, Yamaguchi K, Shi Y, Yu P, Qian F, Chu F, Bentzien F, Cancilla B, Orf J, You A, Laird AD, Engst S, Lee L, Lesch J, Chou YC, Joly AH: Cabozantinib (XL184), a novel MET and VEGFR2 inhibitor, simultaneously suppresses metastasis, angiogenesis, and tumor growth. Mol Cancer Ther 2011, 10:2298-2308

2. Viola D, Cappagli V, Elisei R: Cabozantinib (XL184) for the treatment of locally advanced or metastatic progressive medullary thyroid cancer. Future Oncol 2013, 9:1083-1092.

3. Kurzrock R, Sherman SI, Ball DW, Forastiere AA, Cohen RB, Mehra R, Pfister DG, Cohen EE, Janisch L, Nauling F, Hong DS, Ng CS, Ye L, Gagel RF, Frye J, Muller T, Ratain MJ, Salgia R: Activity of XL184 (Cabozantinib), an oral tyrosine kinase inhibitor, in patients with medullary thyroid cancer. J Clin Oncol 2011, 29:2660-2666.

4. Elisei $R$, Schlumberger MJ, Muller SP, Schoffski P, Brose MS, Shah MH, Licitra $L$, Jarzab B, Medvedev V, Kreissl MC, Niederle B, Cohen EE, Wirth $\sqcup$, Ali $H_{1}$ Hessel C, Yaron Y, Ball D, Nelkin B, Sherman SI: Cabozantinib in progressive medullary thyroid cancer. J Clin Oncol 2013, 31:3639-3646.

5. Boccaccio C, Comoglio PM: Invasive growth: a MET-driven genetic programme for cancer and stem cells. Nat Rev Cancer 2006, 6:637-645

6. Birchmeier C, Birchmeier W, Gherardi E, Vande Woude GF: Met, metastasis, motility and more. Nat Rev Mol Cell Biol 2003, 4:915-925.

7. Shojaei F, Lee JH, Simmons BH, Wong A, Esparza CO, Plumlee PA, Feng J, Stewart AE, Hu-Lowe DD, Christensen JG: HGF/c-Met acts as an alternative angiogenic pathway in sunitinib-resistant tumors. Cancer Res 2010, 70:10090-10100.

8. Kosaka T, Yamaki E, Mogi A, Kuwano H: Mechanisms of resistance to EGFR TKIs and development of a new generation of drugs in non-small-cell lung cancer. J Biomed Biotechnol 2011, 2011:165214.

9. Park S, Choi YL, Sung CO, An J, Seo J, Ahn MJ, Ahn JS, Park K, Shin YK, Erkin OC, Song K, Kim J, Shim YM, Han J: High MET copy number and MET overexpression: poor outcome in non-small cell lung cancer patients. Histol Histopathol 2012, 27:197-207.

10. De Oliveira AT, Matos D, Logullo AF SRDAS, Neto RA, Filho AL, Saad SS: MET is highly expressed in advanced stages of colorectal cancer and indicates worse prognosis and mortality. Anticancer Res 2009, 29:4807-4811.

11. Lengyel E, Prechtel D, Resau JH, Gauger K, Welk A, Lindemann K, Salanti G, Richter T, Knudsen B, Vande Woude GF, Harbeck N: C-Met overexpression in node-positive breast cancer identifies patients with poor clinical outcome independent of Her2/neu. Int J Cancer 2005, 113:678-682.

12. Ahmed SI, Thomas AL, Steward WP: Vascular endothelial growth factor (VEGF) inhibition by small molecules. J Chemother 2004, 16(Suppl 4):59-63.

13. Schenone S, Bondavalli F, Botta M: Antiangiogenic agents: an update on small molecule VEGFR inhibitors. Curr Med Chem 2007, 14:2495-2516.

14. Lien S, Lowman HB: Therapeutic anti-VEGF antibodies. Handb Exp Pharmacol 2008, 181:131-150.

15. Tejpar S, Prenen $\mathrm{H}$, Mazzone M: Overcoming resistance to antiangiogenic therapies. Oncologist 2012, 17:1039-1050. 
16. Smith DC, Smith MR, Sweeney C, Elfiky AA, Logothetis C, Corn PG, Vogelzang NJ, Small EJ, Harzstark AL, Gordon MS, Vaishampayan UN, Haas NB, Spira Al, Lara PN Jr, Lin CC, Srinivas S, Sella A, Schoffski P, Scheffold C, Weitzman AL, Hussain M: Cabozantinib in patients with advanced prostate cancer: results of a phase II randomized discontinuation trial. J Clin Oncol 2013, 31:412-419.

17. Xiang Q, Chen W, Ren M, Wang J, Zhang H, Deng DY, Zhang L, Shang C, Chen Y: Cabozantinib suppresses tumor growth and metastasis in hepatocellular carcinoma by a dual blockade of VEGFR2 and MET. Clin Cancer Res 2014, 20:2959-2970.

18. Choueiri TK, Kumar Pal S, McDermott DF, Morrissey S, Ferguson KC, Holland J, Kaelin WG Jr, Dutcher JP: A phase I study of cabozantinib (XL184) in patients with renal cell cancer. Ann Oncol 2014, 25:1603-1608.

19. Higano CS, Schellhammer PF, Small EJ, Burch PA, Nemunaitis J, Yuh L, Provost N, Frohlich MW: Integrated data from 2 randomized, double-blind, placebocontrolled, phase 3 trials of active cellular immunotherapy with sipuleucel-T in advanced prostate cancer. Cancer 2009, 115:3670-3679.

20. Hodi FS, O'Day SJ, McDermott DF, Weber RW, Sosman JA, Haanen JB, Gonzalez R, Robert C, Schadendorf D, Hassel JC, Akerley W, van den Eertwegh AJ, Lutzky J, Lorigan P, Vaubel JM, Linette GP, Hogg D, Ottensmeier CH, Lebbe C, Peschel C, Quirt I, Clark Jl, Wolchok JD, Weber JS, Tian J, Yellin MJ, Nichol GM, Hoos A, Urba WJ: Improved survival with ipilimumab in patients with metastatic melanoma. N Engl J Med 2010, 363:711-723.

21. Robert C, Ribas A, Wolchok JD, Hodi FS, Hamid O, Kefford R, Weber JS, Joshua AM, Hwu WJ, Gangadhar TC, Patnaik A, Dronca R, Zarour H, Joseph RW, Boasberg P, Chmielowski B, Mateus C, Postow MA, Gergich K, Elassaiss-Schaap J, Li XN, lannone R, Ebbinghaus SW, Kang SP, Daud A: Anti-programmed-death-receptor-1 treatment with pembrolizumab in ipilimumab-refractory advanced melanoma: a randomised dose-comparison cohort of a phase 1 trial. Lancet 2014, 384:1109-1117.

22. Rosenberg SA: IL-2: the first effective immunotherapy for human cancer. $\mathrm{J}$ Immunol 2014, 192:5451-5458.

23. Tarhini AA, Gogas H, Kirkwood JM: IFN-alpha in the treatment of melanoma. J Immunol 2012, 189:3789-3793.

24. Arlen PM, Pazdur M, Skarupa L, Rauckhorst M, Gulley JL: A randomized phase II study of docetaxel alone or in combination with PANVAC-V (vaccinia) and PANVAC-F (fowlpox) in patients with metastatic breast cancer (NCl 05-C-0229). Clin Breast Cancer 2006, 7:176-179.

25. Farsaci B, Kwilas A, Hodge JW: Design, development, and translation of poxvirus-based vaccines for cancer. In Cancer Vaccines: From Research to Clinical Practice. Edited by Bot A, Obrocea M, Marincola F. London, UK: Informa Healthcare; 2011:56-77.

26. Kantoff PW, Schuetz TJ, Blumenstein BA, Glode LM, Bilhartz DL, Wyand M, Manson K, Panicali DL, Laus R, Schlom J, Dahut WL, Arlen PM, Gulley JL, Godfrey WR: Overall survival analysis of a phase II randomized controlled trial of a Poxviral-based PSA-targeted immunotherapy in metastatic castration-resistant prostate cancer. J Clin Oncol 2010, 28:1099-1105.

27. Hodge JW, Ardiani A, Farsaci B, Kwilas AR, Gameiro SR: The tipping point for combination therapy: cancer vaccines with radiation, chemotherapy, or targeted small molecule inhibitors. Semin Oncol 2012, 39:323-339.

28. Kim R, Emi M, Tanabe K, Arihiro K: Tumor-driven evolution of immunosuppressive networks during malignant progression. Cancer Res 2006, 66:5527-5536.

29. Rabinovich GA, Gabrilovich D, Sotomayor EM: Immunosuppressive strategies that are mediated by tumor cells. Annu Rev Immunol 2007, 25:267-296

30. Ardiani A, Farsaci B, Rogers CJ, Protter A, Guo Z, King TH, Apelian D, Hodge JW: Combination therapy with a second-generation androgen receptor antagonist and a metastasis vaccine improves survival in a spontaneous prostate cancer model. Clin Cancer Res 2013, 19:6205-6218.

31. Chakraborty M, Abrams SI, Camphausen K, Liu K, Scott T, Coleman CN, Hodge JW: Irradiation of tumor cells up-regulates Fas and enhances CTL lytic activity and CTL adoptive immunotherapy. J Immunol 2003, 170:6338-6347.

32. Chakraborty M, Abrams SI, Coleman CN, Camphausen K, Schlom J, Hodge JW: External beam radiation of tumors alters phenotype of tumor cells to render them susceptible to vaccine-mediated T-cell killing. Cancer Res 2004, 64:4328-4337.

33. Gameiro SR, Caballero JA, Hodge JW: Defining the molecular signature of chemotherapy-mediated lung tumor phenotype modulation and increased susceptibility to T-cell killing. Cancer Biother Radiopharm 2012, 27:23-35.

34. Farsaci B, Higgins JP, Hodge JW: Consequence of dose scheduling of sunitinib on host immune response elements and vaccine combination therapy. Int J Cancer 2012, 130:1948-1959.

35. Farsaci B, Sabzevari H, Higgins JP, Di Bari MG, Takai S, Schlom J, Hodge JW: Effect of a small molecule BCL-2 inhibitor on immune function and use with a recombinant vaccine. Int J Cancer 2010, 127:1603-1613.

36. Gameiro SR, Caballero JA, Higgins JP, Apelian D, Hodge JW: Exploitation of differential homeostatic proliferation of T-cell subsets following chemotherapy to enhance the efficacy of vaccine-mediated antitumor responses. Cancer Immunol Immunother 2011, 60:1227-1242.

37. Gameiro SR, Jammeh ML, Wattenberg MM, Tsang KY, Ferrone S, Hodge JW: Radiation-induced immunogenic modulation of tumor enhances antigen processing and calreticulin exposure, resulting in enhanced T-cell killing. Oncotarget 2014, 5:403-416.

38. Gameiro SR, Higgins JP, Dreher MR, Woods DL, Reddy G, Wood BJ, Guha C, Hodge JW: Combination therapy with local radiofrequency ablation and systemic vaccine enhances antitumor immunity and mediates local and distal tumor regression. PLoS One 2013, 8:e70417.

39. You WK, Sennino B, Williamson CW, Falcon B, Hashizume H, Yao LC, Aftab DT, McDonald DM: VEGF and c-Met blockade amplify angiogenesis inhibition in pancreatic islet cancer. Cancer Res 2011, 71:4758-4768.

40. Sennino B, Ishiguro-Oonuma T, Wei Y, Naylor RM, Williamson CW, Bhagwandin V, Tabruyn SP, You WK, Chapman HA, Christensen JG, Aftab DT, McDonald DM: Suppression of tumor invasion and metastasis by concurrent inhibition of c-Met and VEGF signaling in pancreatic neuroendocrine tumors. Cancer Discov 2012, 2:270-287.

41. Coudriet GM, He J, Trucco M, Mars WM, Piganelli JD: Hepatocyte growth factor modulates interleukin-6 production in bone marrow derived macrophages: implications for inflammatory mediated diseases. PLoS One 2010, 5:e15384

42. Okunishi K, Dohi M, Nakagome K, Tanaka R, Mizuno S, Matsumoto K, Miyazaki J, Nakamura T, Yamamoto K: A novel role of hepatocyte growth factor as an immune regulator through suppressing dendritic cell function. J Immunol 2005, 175:4745-4753.

43. Singhal E, Sen P: Hepatocyte growth factor-induced c-Src-phosphatidylinositol 3-kinase-AKT-mammalian target of rapamycin pathway inhibits dendritic cell activation by blocking IkappaB kinase activity. Int J Biochem Cell Biol 2011, 43:1134-1146.

44. Apolo A, Tomita Y, Lee M, Lee S, Frosch A, Steinberg S, Gulley JL, Schlom J, Bottaro D, Trepel J: Effect of cabozantinib on immunosuppressive subsets in metastatic urothelial carcinoma. J Clin Oncol 2014, 32(5s):abstr 4501.

45. Overwijk WW: Breaking tolerance in cancer immunotherapy: time to ACT. Curr Opin Immunol 2005, 17:187-194.

46. Sato E, Olson SH, Ahn J, Bundy B, Nishikawa H, Qian F, Jungbluth AA, Frosina D, Gnjatic S, Ambrosone C, Kepner J, Odunsi T, Ritter G, Lele S, Chen YT, Ohtani H, Old LJ, Odunsi K: Intraepithelial CD8+ tumor-infiltrating lymphocytes and a high CD8+/regulatory $T$ cell ratio are associated with favorable prognosis in ovarian cancer. Proc Natl Acad Sci U S A 2005, 102:18538-18543.

47. Sinicrope FA, Rego RL, Ansell SM, Knutson KL, Foster NR, Sargent DJ: Intraepithelial effector (CD3+)/regulatory (FoxP3+) T-cell ratio predicts a clinical outcome of human colon carcinoma. Gastroenterology 2009, 137:1270-1279.

48. Huang Y, Yuan J, Righi E, Kamoun WS, Ancukiewicz M, Nezivar J, Santosuosso M, Martin JD, Martin MR, Vianello F, Leblanc P, Munn LL, Huang P, Duda DG, Fukumura D, Jain RK, Poznansky MC: Vascular normalizing doses of antiangiogenic treatment reprogram the immunosuppressive tumor microenvironment and enhance immunotherapy. Proc Natl Acad Sci U S A 2012, 109:17561-17566.

49. Hodge JW, Grosenbach DW, Aarts WM, Poole DJ, Schlom J: Vaccine therapy of established tumors in the absence of autoimmunity. Clin Cancer Res 2003, 9:1837-1849.

50. Clarke P, Mann J, Simpson JF, Rickard-Dickson K, Primus FJ: Mice transgenic for human carcinoembryonic antigen as a model for immunotherapy. Cancer Res 1998, 58:1469-1477.

51. Robbins PF, Kantor JA, Salgaller M, Hand PH, Fernsten PD, Schlom J: Transduction and expression of the human carcinoembryonic antigen gene in a murine colon carcinoma cell line. Cancer Res 1991, 51:3657-3662 
52. Hodge JW, Poole DJ, Aarts WM, Gomez Yafal A, Gritz L, Schlom J: Modified vaccinia virus ankara recombinants are as potent as vaccinia recombinants in diversified prime and boost vaccine regimens to elicit therapeutic antitumor responses. Cancer Res 2003, 63:7942-7949.

53. Boehm AL, Higgins J, Franzusoff A, Schlom J, Hodge JW: Concurrent vaccination with two distinct vaccine platforms targeting the same antigen generates phenotypically and functionally distinct T-cell populations. Cancer Immunol Immunother 2010, 59:397-408.

54. Kudo-Saito C, Schlom J, Hodge JW: Induction of an antigen cascade by diversified subcutaneous/intratumoral vaccination is associated with antitumor responses. Clin Cancer Res 2005, 11:2416-2426.

doi:10.1186/s12967-014-0294-y

Cite this article as: Kwilas et al:: Dual effects of a targeted small-molecule inhibitor (cabozantinib) on immune-mediated killing of tumor cells and immune tumor microenvironment permissiveness when combined with a cancer vaccine. Journal of Translational Medicine 2014 12:294.

\section{Submit your next manuscript to BioMed Central and take full advantage of:}

- Convenient online submission

- Thorough peer review

- No space constraints or color figure charges

- Immediate publication on acceptance

- Inclusion in PubMed, CAS, Scopus and Google Scholar

- Research which is freely available for redistribution 